\title{
A New Tool for Assessing Bladder Outlet Obstruction
}

\section{S. Emara*}

*Clinical Fellow in Reconstructive Urology, Western general hospital, Edinburgh, United Kingdom.

${ }^{\star}$ Corresponding author: Dr. Shady Emara, Clinical Fellow in Reconstructive Urology, Western general hospital, Edinburgh; Tel: 07440280125; Email: shady.emara@ nhs.net

Received: December 21, 2019; Accepted: December 23, 2019; Published: January 25, 2020

\section{Abstract}

Objective: Assessing the role of transrectal Doppler ultrasound in estimating degree of bladder outlet obstruction, in patients with benign prostatic hyperplasia.

Methods: Fifty two patients aged from 55 to 70 with the clinical diagnosis of BPH were recruited. Patients with cancer prostate, neurogenic bladder, previous lower urinary tract intervention, were excluded. Urologic evaluation included, thorough history, IPSS, neurologic examination, digital rectal examination, urine analysis, PSA, uroflowmetry, transrectal doppler ultrasonography. The correlations were analysed between the resistive index of prostatic capsular artery, and maximum flow rate (Qmax).

Results: A significant increase in RI correlated to decrease in Qmax ( $r=-0.398, p<0.016)$ was found. Also there was significant increase in RI correlated to increase in IPSS $(r=0.535, \mathrm{p}<0.001)$. AS regard Qmax, there was significant decrease in Qmax correlated to increase in IPSS $(\mathrm{r}=-0.654, \mathrm{p}<0.001)$.

\begin{tabular}{|l|c|c|c|c|c|c|}
\hline \multicolumn{7}{|c|}{ Rescriptive Statistics } \\
\hline & \multicolumn{7}{|c|}{ Range } & Mean & \pm & SD \\
\hline Age(year) & 55 & - & 70 & 63.863 & \pm & 4.643 \\
\hline IPSS & 1 & - & 35 & 19.882 & \pm & 9.361 \\
\hline Q Max(ml/sec) & 2.6 & - & 17.9 & 9.097 & \pm & 4.591 \\
\hline PSA(ng/ml) & 0.9 & - & 33 & 10.903 & \pm & 8.776 \\
\hline Total gland volume(gm) & 20 & - & 295 & 82.922 & \pm & 45.808 \\
\hline Adenoma(gm) & 9 & - & 202 & 51.524 & \pm & 35.149 \\
\hline Residual urine(ml) & 0 & - & 450 & 77.030 & \pm & 96.311 \\
\hline RI & 0.29 & - & 0.95 & 0.728 & \pm & 0.110 \\
\hline
\end{tabular}

Conclusion: Transrectal Doppler can be used as a tool to measure degree of bladder outlet obstruction, through measuring resistive index of prostatic capsular artery.

\section{Introduction}

Arterial resistivity index (also called as Resistive index, abbreviated as RI), developed by LeandrePourcelot, in 1982. Which is a measure of pulsatile blood flow that reflects the resistance to blood flow caused by microvascular bed distal to the site of measurement [1]. Owing to advent of Doppler imaging, RI measurement in patients with LUTS has become a promising parameter for the diagnosis of BPH. It was found that a hyperplastic prostate tissue pushed the capsule out as it grew thus increasing the intraprostatic pressure as well as RI. The increase of the intraprostatic pressure is equally distributed throughout the whole prostate, so the increase of RI was found in both peripheral and transition zones [1]. Also as regard PDUS, the technique has been found to enhance prostate cancer detection. Spectral waveform measurements by power Doppler TRUS may be promising for the differentiation of PCa in patients with benign diseases as an adjunct to systematic sampling in the presence of ultrasonographically detectable lesions accompanied by positive rectal examination findings and suspicious PSA levels [2].

Resistive index of prostatic capsular artery for evaluating obstruction

It was used for the first time by Kojima and his colleagues in the differentiation of the normal prostate in $\mathrm{BPH}$ patients. [1]

How BPH increases RI of prostatic capsular artery? 
How prostatic RI increases in $\mathrm{BPH}$ patients, is still not completely understood, may be the hypertrophied prostate squeezes the capsule outwards, which results in an increase in intraprostatic pressure and prostatic RI. [3]

\section{Supporting Evidence} [1]

This is supported by the decrease in RI value after a prostatectomy.

Doxazosin treatment significantly decreased prostatic RI in BPH patients. [4]

It was shown that the RI increases significantly correlated to the increase in prostatic volume, and that there was a significant difference in RI between patients with normal prostate and those with BPH. [1]

Which branch of prostatic artery to measure RI and which zone?

An increase of the RI of capsular arteries correlated with prostatic parameters in patients with $\mathrm{BPH}$, however, no correlation between the RI of urethral arteries and prostatic parameters was found. The findings suggested that the RI of capsular arteries may become the index for measuring lower urinary obstruction in the future. [5]

How is RI measured?

The indices depend on ratios involving the peak systolic velocity (PSV), the end diastolic velocity (EDV) and mean velocity (MV) through one cycle. RI is one of the primary indices used clinically and is calculated through the following equation. [1]

$$
\mathrm{RI}=\mathrm{PSV}-\mathrm{EDV}
$$

\section{Power Doppler versus color Doppler:}

\section{Weakness points:}

It is hypothesized that an enlargement of the median lobe may not impact RI value as it does not impose increased resistance to capsular arteries. The association of intravesical prostatic protrusion (IPP) could add for a more precise diagnosis in this scenario [1].

\section{Patients and Methods:}

This study was conducted on 52 patients presenting with LUTS due to $\mathrm{BPH}$, to the outpatient clinic at Kasr Al-Aini University Hospital, Mansoura Urology and Nephrology Centre, and The National Institute of Urology and Nephrology.

\section{Patients}

Inclusion criteria: Patients aged from 55 to 70 years presenting with LUTS due to BPH.

Exclusion criteria: Patients who had one or more of the following were excluded from the study: Patients with prostate cancer (In cases of abnormal PSA, or abnormal DRE, TRUS biopsy was done to exclude cancer). Patients with history of lower urinary tract interventions. Patients with neurogenic bladder (based on history, clinical examination and post voiding residual volumes).

Methods: All patients were subjected to:
Thorough history taking

Full history was taken from all cases as regards:

1. Personal history: This included age, occupation, special habits of medical importance and sexual history.

a. Past history:

b. Surgical history: previous lower urinary tract interventions.

c. Medical history: Diabetes Mellitus, Hypertension, and neurogenic disorders.

d. Family history: Cancer prostate

2. Presenting complaint: All patients had a self-administered, validated Arabic version of IPSS questionnaire.

3. Full clinical examination

a. Each patient was thoroughly examined:

b. General examination: It was done in all patients with including neurologic examination.

c. Genitourinary examination: Digital rectal examination was done to every patient to assess prostate size, surface, and consistency, and also assessing anal tone, or as a part of bulbocavernosus reflex test.

4. Labs

5. Urine analysis and culture.

6. PSA (free and total).

7. Uroflowmetry: It was done to assess the urine flow and measure the Qmax. Cases in which detrouserhypocontractility was suspected (due to neurogenic insult, diabetes or very old age $>70$ ), were omitted. Transrectal Ultrasonography and Doppler: To measure size of prostate, adenoma, residual volume. Doppler was used to measure resistive index of prostatic capsular artery. The machine used is BK medical flex 400 .

8. Statistical Analysis: Data were collected, verified, revised then edited on personal computer. Categorical variables were expressed as absolute and relative frequencies while continuous variables were presented as mean values \pm standard deviation (SD). Comparisons were made between continuous and ordinal variable using student $t$ test, comparisons were made between 2 continuous variables using Pearson's correlation. Sensitivity and Specificity was calculated using chi-square test. Statistical analysis was performed using SPSS (statistical package version sixteen). Difference was considered statistically significant at a $\mathrm{P}$ value $<$ 0.05 and highly significant at $\mathrm{P}$ value $<0.01$.

\section{Results}

Number of Patients enrolled in this study was 52 patients .Range of age was $55-70$ with mean age $63.8 \pm 4.6$. Eight parameters were studied and the values of these studies were summarized in table (3). 
Table 1. Summary of result

\begin{tabular}{|l|c|c|c|c|c|c|}
\hline \multicolumn{7}{|c|}{ Descriptive Statistics } \\
\hline & \multicolumn{7}{|c|}{ Range } & Mean & \pm & SD \\
\hline Age(year) & 55 & - & 70 & 63.863 & \pm & 4.643 \\
\hline IPSS & 1 & - & 35 & 19.882 & \pm & 9.361 \\
\hline Q Max(ml/sec) & 2.6 & - & 17.9 & 9.097 & \pm & 4.591 \\
\hline PSA(ng/ml) & 0.9 & - & 33 & 10.903 & \pm & 8.776 \\
\hline $\begin{array}{l}\text { Total gland } \\
\text { volume(gm) }\end{array}$ & 20 & - & 295 & 82.922 & \pm & 45.808 \\
\hline Adenoma(gm) & 9 & - & 202 & 51.524 & \pm & 35.149 \\
\hline Residual urine(ml) & 0 & - & 450 & 77.030 & \pm & 96.311 \\
\hline RI & 0.29 & - & 0.95 & 0.728 & \pm & 0.110 \\
\hline
\end{tabular}

The mean patient's age was 63.86 years, the mean IPSS was 19.88, the mean Qmax was $9.09 \mathrm{ml} / \mathrm{sec}$, the mean PSA was $10.9 \mathrm{ng} / \mathrm{ml}$, the mean total gland volume was $82.92 \mathrm{gm}$, the mean adenoma volume was $51.52 \mathrm{gm}$, the mean residual urine volume was $77.03 \mathrm{ml}$, the mean resistive index was 0.73 .

Mean resistive index for obstructed group was 0.76 , while for the non obstructed group was 0.69 .

Normal RI of prostatic capsular artery is $0.55-0.71$ [6].

Table 2. Correlation between Qmax and other factors in question for being indicator of degree of obstruction.

\begin{tabular}{|l|c|c|}
\hline \multirow{2}{*}{} & \multicolumn{2}{|c|}{ Correlations } \\
\hline & $\mathbf{2}$ & Max \\
\cline { 2 - 3 } & $\mathbf{2}$ & 0.923 \\
\hline Age & -0.017 & $<0.001^{*}$ \\
\hline PSA & -0.654 & 0.955 \\
\hline P. Size & 0.013 & 0.519 \\
\hline Adenoma & -0.111 & 0.886 \\
\hline Residual V & -0.201 & 0.269 \\
\hline
\end{tabular}

The only statistical significance was found in correlation between Qmax and IPSS ( $r=$ $-0.654, \mathrm{p}<0.001)$.

No statistical significance was found in correlation between Qmax and age $(r=-0.017, p$ $=0.923)$, no statistical significance was found in correlation between Qmax and PSA $(\mathrm{r}=$ $0.013, p=0.955)$, no statistical significance was found in correlation between Qmax and prostate size $(\mathrm{r}=-0.111, \mathrm{p}=0.519)$, no statistical significance was found in correlation between Qmax and adenoma volume $(r=-0.028, p=0.866)$, no statistical significance was found in correlation between $\mathrm{Qmax}$ and residual volume of urine $(\mathrm{r}=-0.201, \mathrm{p}=$ $0.269)$.
Table 3. Correlation between RI, Qmax and other factors in question for being indicator of degree of obstruction.

\begin{tabular}{|l|c|c|}
\hline \multirow{2}{*}{} & \multicolumn{2}{|c|}{ RI } \\
\cline { 2 - 3 } & $\mathbf{r}$ & P-value \\
\hline Q Max & -0.398 & $0.016^{*}$ \\
\hline Age & 0.008 & 0.954 \\
\hline IPSS & 0.535 & $<0.001^{*}$ \\
\hline PSA & -0.166 & 0.347 \\
\hline P. Size & 0.023 & 0.875 \\
\hline Adenoma & 0.071 & 0.656 \\
\hline Residual V & 0.243 & 0.173 \\
\hline
\end{tabular}

Statistical significance was found in correlation between RI and Qmax $(r=-0.398, p=$ $0.016)$, and between RI and IPSS $(r=-0.398, \mathrm{p}=0.016)$.

Table 4. Range of resistive index of capsular prostatic artery for each group of IPSS.

\begin{tabular}{|l|c|c|c|}
\hline \multicolumn{1}{|c|}{ Group } & $\begin{array}{c}\text { Number of } \\
\text { patients }\end{array}$ & $\begin{array}{c}\text { Minimum } \\
\text { resistive index }\end{array}$ & $\begin{array}{c}\text { Maximum } \\
\text { resistive index }\end{array}$ \\
\hline Mild & 4 & 0.29 & 0.67 \\
\hline Moderate & 21 & 0.55 & 0.89 \\
\hline Severe & 27 & 0.61 & 0.95 \\
\hline
\end{tabular}

The patients were divided according to IPSS as follows: mild symptoms $(0-7)$, moderate symptoms (8-19), and severe symptoms (20-35) groups. In the mild symptoms group RI ranged from 0.29 to 0.67 , in the moderate symptoms group RI ranged from 0.55 to 0.89 , in the severe symptoms group RI ranged from 0.61 to 0.95 .

Table 5. Calculating sensitivity, specificity, PPV, and NPV of RI of prostatic capsular artery.

\begin{tabular}{|c|c|c|c|}
\hline & $\begin{array}{c}\text { Diseased } \\
\text { (obstructed, } \\
\text { Qmax }<10 \mathrm{ml} / \mathrm{sec} \text { ) }\end{array}$ & $\begin{array}{c}\text { Non diseased } \\
\text { (not obstructed, } \\
\text { Qmax } \geq 10 \mathrm{ml} / \mathrm{sec} \text { ) }\end{array}$ & Total \\
\hline $\begin{array}{l}+\mathrm{ve} \\
(\mathrm{RI}>0.71)\end{array}$ & 20 & 6 & 26 \\
\hline \multirow[t]{2}{*}{$\begin{array}{l}\text {-ve } \\
(\mathrm{RI} \leq 0.71)\end{array}$} & 8 & 18 & 26 \\
\hline & 28 & 24 & \\
\hline
\end{tabular}

Twenty six patients had resistive index more than $0.71,20$ of them were truly obstructed i.e., Qmax less than $10 \mathrm{ml} / \mathrm{sec}$, and 6 of them were not obstructed, i.e., Qmax more than $10 \mathrm{ml} / \mathrm{sec}$. On the otherside there were also 26 patients whose resistive index was less than or equal $0.71,18$ of them were not obstructed Qmax more than $10 \mathrm{ml} / \mathrm{sec}$, but there was 8 obstructed Qmax less than $10 \mathrm{ml} / \mathrm{sec}$.

$\begin{array}{ll}\text { Sensitivity }=71 \% & \text { PPV }=77 \% \\ \text { Specificity }=75 \% & \text { NPV }=69 \%\end{array}$

At RI 0.75 ,

Sensitivity $=57 \% \quad$ PPV $=88 \%$

Specificity $=89 \% \quad \mathrm{NPV}=60 \%$

At RI 0.8,

Sensitivity $=38 \% \quad$ PPV $=100 \%$

Specificity $=100 \% \quad \mathrm{NPV}=54 \%$

At RI 0.85,

Sensitivity $=27 \% \quad \mathrm{PPV}=100 \%$

Specificity $=100 \% \quad \mathrm{NPV}=50 \%$ 
Table 6. Sensitivity, specificity, PPV and NPV of RI of prostatic capsular artery at different resistive indices.

\begin{tabular}{|l|c|c|c|c|}
\hline \multicolumn{1}{|c|}{ RI } & Sensitivity & Specificity & PPV & NPV \\
\hline 0.75 & 57 & 89 & 88 & 60 \\
\hline 0.8 & 38 & 100 & 100 & 54 \\
\hline 0.85 & 27 & 100 & 100 & 50 \\
\hline
\end{tabular}

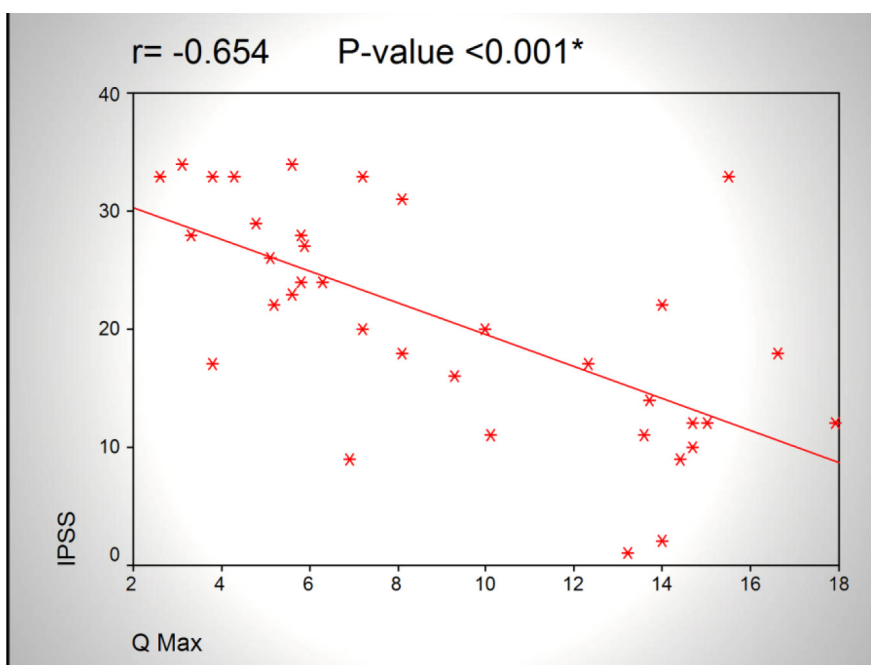

Figure 1. Scatter chart showing an inversely proportional relationship between Qmax and IPSS.

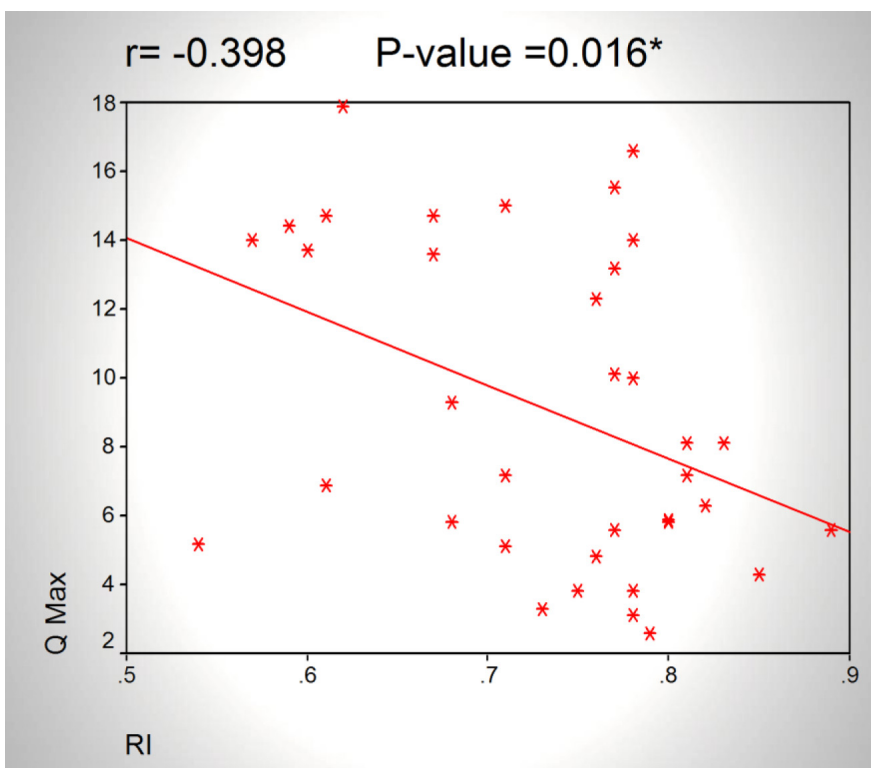

Figure 2. Scatter chart showing an inversely proportional relationship between RI and Qmax.

\section{Discussion}

Thanks to doppler imaging invention RI measurement in patients with LUTS has become a promising parameter for the diagnosis of $\mathrm{BPH}$. It was found that a hyperplastic prostate tissue pushed the capsule out as it grew thus increasing the intraprostatic pressure as well as RI. The increase of the intraprostatic pressure is equally distributed throughout the whole prostate, so the increase of RI was found in both peripheral and transition zones [1]. In a Turkish study, the authors have intervened with Afluzosin XL $10 \mathrm{mg}$ given to 34 patients with LUTSs for a month. They have found significant relationship between RI, Qmax, IPSS, and PSA. The mean RI value was $0.72+0.06$ before medication and decreased significantly to $0.66+0.04$ after the treatment $(\mathrm{p}<0.05)$. There was no relationship between RI and age $(\mathrm{r}=0.23, \mathrm{p}>0.05)$. This study also depended on uroflowmetry rather than urodynamics [7].

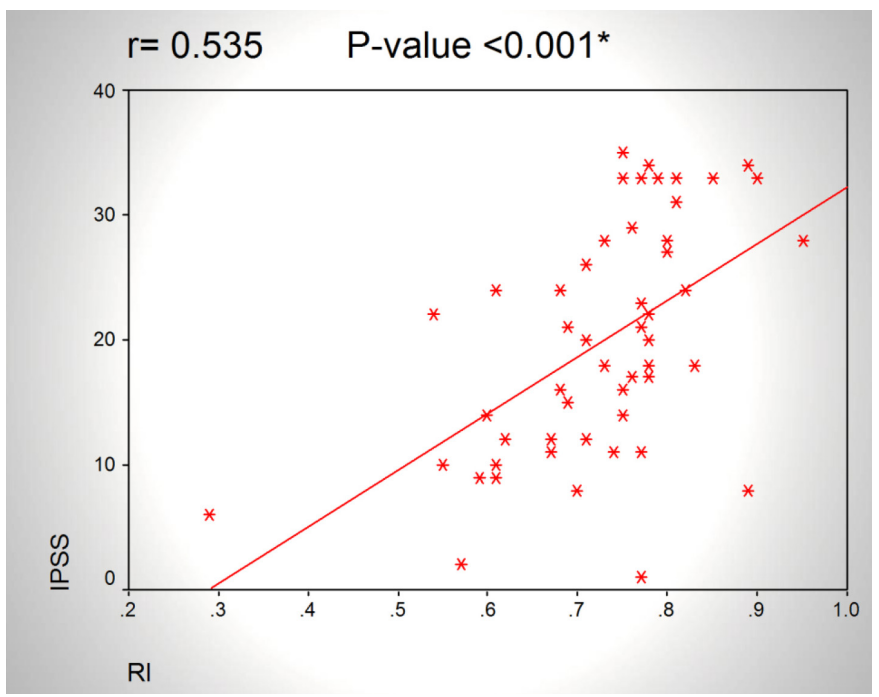

Figure 3. Scatter chart showing a directly proportional relationship between RI and IPSS. \#Sensitivity and specificity of RI:

Positivity of the test was assumed to be RI $>0.71$ (the upper limit of RI of normal prostatic capsular artery from Kojima study).

The diseased group was assumed to be those with Qmax $<10 \mathrm{ml} / \mathrm{sec}$. (according to cut off established by Nitti et al $90 \%$ of men with a Qmax of less than $10 \mathrm{~mL} / \mathrm{sec}$ are obstructed).

In a study by Kojima $M$ and colleges, they investigated the relationship between the resistive index (RI) of the prostate as measured by transrectal power Doppler with age, transrectal ultrasound planimetry and parameters of pressure-flow study. A total of 140 elderly patients with lower urinary tract symptoms and no previous treatment for lower urinary tract symptoms, prostate cancer, bladder dysfunction or urethral stricture were investigated. A mean $\mathrm{RI}$ of $0.72 \pm 0.06$ (range $0.59-0.88$ ) was measured in patients with BPH versus a mean value of $0.64 \pm 0.04$ (range $0.55-0.71$ ) in those with a normal prostate $(\mathrm{P}<0.0001)$. The strongest correlation was found between RI and pdet $(r=0.401, P<0.005)$, followed by pdetQmax $(r=$ $0.360, \mathrm{P}<0.01)$ and the Abrams-Griffiths number $(\mathrm{r}=0.330, \mathrm{P}<0.05)$. This study depended on urodynamics to obtain the Pdet, thus bladder outlet obstruction index BOOI could be calculated and correlated with the RI. On the otherside, the authors didn't mention IPSS as one of parameters for judging degree of bladder outlet obstruction [6]. The reason for the increase in RI in BPH has not been established, but it may be because the growing hypertrophic prostate pushes the capsule outward and thereby increases intraprostatic pressure and RIs [8].

In our study, 28 patients out of 52 (54\%) were diagnosed obstructed i.e., Qmax less than $10 \mathrm{ml} / \mathrm{sec}, 21$ (40\%) patients were equivocal i.e., 
Qmax 10-15 $\mathrm{ml} / \mathrm{sec}$, and 3 patients (6\%) were not obstructed i.e., Qmax more than $15 \mathrm{ml} / \mathrm{sec}$. We have correlated between the resistive index, Qmax, IPSS, PSA, age, prostate volume, and adenoma volume. There was a significant increase in RI correlated to decrease in Qmax $(\mathrm{r}=-0.398, \mathrm{p}<0.016)$. Also there was significant increase in RI correlated to increase in IPSS $(\mathrm{r}=0.535, \mathrm{p}<0.001)$. AS regard Qmax, there was significant decrease in Qmax correlated to increase in IPSS $(\mathrm{r}=-0.654, \mathrm{p}<0.001)$.

Conversely, no relation was found between degree of obstruction and other parameters; age, PSA, prostate volume, adenoma volume, residual volume.

At a cutoff of 0.71 the resistive index distinguished patients with and without bladder outlet obstruction with $71 \%$ sensitivity and $75 \%$ specificity, reflecting BOO severity in patients with BPH. At cut off of 0.8 , RI is highly specific $100 \%$, so it can strongly confirm the diagnosis of obstruction. Our results are consistent with those of Zhang X et al 2012, at nearly equal resistive index ( 0.71 in our study and 0.69 in Zhang study), the resistive index had sensitivity $71 \%$ compared to $78 \%$ in Zhang study. While specificity was $75 \%$ in our study, it was $86 \%$ in Zhang study.

The value of measuring the prostatic resistive index vs. pressureflow studies in the diagnosis of bladder outlet obstruction caused by benign prostatic hyperplasia: TRUS is less invasive, cheaper and less time-consuming than pressure flow study, and measures prostatic size, which is useful in planning management [9]. Spectral waveform measurements by power Doppler transrectal ultrasonography may be useful in differentiating prostate cancer from benign hypertrophy [2]. One point of criticism was that we used uroflowmtery instead of urodynamics for assessing bladder outlet obstruction. However we obviated cases that may have detrouserhypocontractlity by excluding patients older than 70 years, excluding patients with suspected neurogenic element, and patients with very large residual volumes suggesting chronic retention.

Comparing results of our study with those of other studies:

\section{Mean age:}

Table 7. Comparing patient age in different studies

\begin{tabular}{|l|c|}
\hline \multicolumn{1}{|c|}{ Study } & Mean age (years) \\
\hline Our study & 63.9 \\
\hline Osama et al 2012 & 66.8 \\
\hline Hitoshi et al 2009 & 71.1 \\
\hline Zhang X et al 2012 & 67.5 \\
\hline
\end{tabular}

\section{Mean prostatic volume:}

Table 8. Comparing prostate volume in different studies.

\begin{tabular}{|l|c|}
\hline \multicolumn{1}{|c|}{ Study } & Mean prostatic volume (grams) \\
\hline Our study & 82.9 \\
\hline Osama et al 2012 & 75.1 \\
\hline Hitoshi et al 2009 & 71.6 \\
\hline Zhang X et al 2012 & 53.5 \\
\hline
\end{tabular}

\section{Limitations of the study}

When comparing values of RIs between IPSS groups (mild, moderate, severe), there was overlap between groups, i.e., some patients with mild symptoms had higher RI than some patients with moderate symptoms, and some patients with moderate symptoms had higher RI than some patients with severe symptoms, we attribute this overlap to the following:

Cases with only enlarged median lobe. It is hypothesized that an enlargement of the median lobe may not impact RI value as it does not impose increased resistance to capsular arteries. The association of intravesical prostatic protrusion (IPP) could add for a more precise diagnosis in this scenario [1]. There is some sort of selection bias. This group of age (55-70) mostly, will have cardiovascular risk factors placing further burdens on their prostatic blood flow. Prostate RI values are highly linked to overall metabolic syndrome and smoking in addition to $\mathrm{BPH}[10]$. So, we recommend a study upon younger population in conjunction with cardiologists for assessing cardiovascular risk factors, thus excluding all factors than can influence RI other than pathology of BPH. IPSS questionnaire is sometimes a difficult task for the patient, and they tend to just complete it carelessly, this is due to many factors: poor vision in old age (which is the case of most patients with $\mathrm{BPH}$ ), low level of education, or lack of interest.

\section{Conclusion}

RI can be used as a modality for assessing BPH patients and anticipating success of surgery. RI is a good indicator for degree of bladder outlet obstruction due to $\mathrm{BPH}$, rather than other parameters as prostate volume, adenoma volume, residual volume, and PSA. Further research in this field will even allow the use of this modality to investigate other pathologies affecting the prostate and can be used also to evaluate the outcome of management.

\section{Recommendation}

We recommend a study upon younger population in conjunction with cardiologists for assessing cardiovascular risk factors like atherosclerosis, hyperlipdemia, and smoking. Thus excluding all factors than can influence RI other than pathology of BPH. Further studies in larger cohorts are required to validate the reliability of prostate capsular artery RI.

\section{References}

1. Abdelwahab O, El-Barky E, Khalil MM, Kamar A (2012) Evaluation of the resistive index of prostatic blood flow in benign prostatic hyperplasia. International braz $j$ urol 38: 255-257. [Crossref]

2. Ahmet Tuncay Turgut, Esin Ölçücüoğlu, Pinar Koşar, Pinar Özdemir Geyik, Uğur Koşar, et al. (2007) et al. Power Doppler Ultrasonography of the Feeding Arteries of the Prostate Gland. Journal of Ultrasound in Medicine 26: 875-883.

3. Yencilek E, Koyuncu H, Arslan D, Bastug Y (2014) The measurement of the prostatic Resistive Index is a reliable ultrasonographic tool to stratify symptoms of patients with benign prostatic hyperplasia. Medical Ultrasonography 16: 208-213. [Crossref]

4. Ozden C, Gunay I, Deren T, Bulut S, Koparal S, et al. (2009) Effect of Doxazosin on prostatic resistive index in patients with benign prostate hyperplasia. Firat Tlp Dergisi 14: 171-174.

5. Tsuru N, Kurita Y, Masuda H, Suzuki K, Fujita K (2002) Role of Doppler ultrasound and resistive index in benign prostatic hypertrophy. International Journal of Urology 9: 427-430. [Crossref] 
6. Kojima M, Ochiai A, Naya Y, Okihara K, Ukimura O, et al. (2000) Doppler Resistive Index in Benign Prostatic Hyperplasia: Correlation with Ultrasonic Appearance of the Prostate and Infravesical Obstruction. European Urology 37: 436-442. [Crossref]

7. Ayhan Karaköse, Turgut Alp, Numan Doğu Güner, Bekir Aras, Sabahattin Aydın (2010) The role of Doppler ultrasonography and resistive index in the diagnosis and treatment of benign prostate hyperplasia. TürkÜrolojiDergisi / Turkish Journal of Urology 36: 292-297.

8. Kwon SY, Ryu JW1, Choi DH, Lee KS (2016) Clinical Significance of the Resistive Index of Prostatic Blood Flow According to Prostate Size in Benign Prostatic Hyperplasia. International Neurourology Journal 20: 75-80. [Crossref]
9. Aldaqadossi HA, Elgamal SA, Saad M (2012) The value of measuring the prostatic resistive index vs. pressure-flow studies in the diagnosis of bladder outlet obstruction caused by benign prostatic hyperplasia. Arab Journal of Urology 10: 186-191. [Crossref]

10. Baykam MM, Aktas BK, Bulut S, Ozden C, Deren T, et al. (2015) Association between prostatic resistive index and cardiovascular risk factors in patients with benign prostatic hyperplasia. The Kaohsiung Journal of Medical Sciences 31: 194-198. [Crossref]

\section{Citation:}

Shady Emara (2019) A New Tool for Assessing Bladder Outlet Obstruction. Integr J Nephro Urol Stud Volume1(1): 1-6. 